\title{
Symptomatic Intraosseous Vascular Malformation of Infraorbital Rim: A Case Report With Literature Survey
}

\author{
REINHARD E. FRIEDRICH ${ }^{1}$, ULRICH GRZYSKA ${ }^{2}$, FELIX K. KOHLRUSCH ${ }^{1}$, \\ SIMON VON KROGE ${ }^{3}$, TOBIAS VOLLKOMMER ${ }^{1}$ and ANDREAS M. LUEBKE ${ }^{4}$ \\ ${ }^{1}$ Oral and Craniomaxillofacial Surgery, Eppendorf University Hospital, \\ University of Hamburg, Hamburg, Germany; \\ ${ }^{2}$ Department of Neuroradiology, Eppendorf University Hospital, University of Hamburg, Hamburg, Germany; \\ ${ }^{3}$ Department of Osteology and Biomechanics, \\ Eppendorf University Hospital, University of Hamburg, Hamburg, Germany; \\ ${ }^{4}$ Institute of Pathology, Eppendorf University Hospital, University of Hamburg, Hamburg, Germany
}

\begin{abstract}
Background/Aim: Intraosseous orbital hemangiomas or vascular malformations (VM) are rare. This report is intended to complement the experience of diagnosing and treating a rare vascular lesion at this site. Special attention is paid to threedimensional imaging and the morphological distinction between the two entities in this location. Case Report: A 54-year-old female was examined and surgically treated for an exophytic firm mass of the infraorbital, which had become palpable as a hard mass due to growth in size. At first, a bone tumor, for example, an osteoma, was suspected. Intraoperatively, an osseous expansion with distinct fenestrations of the newly grown bone's surface, was detected. The lesion was firmly attaching to the orbital rim. The densely vascularized tumor was well defined to the soft tissues but had grown in continuity from the orbital floor and rim. Vascularized cavities caused the tumor to have a slightly reddish color. The histological examination confirmed the suspicion of the lesion's vascular origin. The lesion's immunohistochemical expression profile approved the final diagnosis of intraosseous VM. Conclusion: The symptoms of intraosseous vascular lesions of the orbit are determined by location and size. Modern imaging techniques facilitate the estimation of tumor-like expansion of lesions. However, the imaging characteristics of intraosseous vascular lesions are very
\end{abstract}

This article is freely accessible online.

Correspondence to: Prof. R.E. Friedrich, MD, DMD, Ph.D., Oral and Craniomaxillofacial Surgery, Eppendorf University Hospital, University of Hamburg, Martinist, 52, 20246 Hamburg, Germany. Tel: +49 40741053259, e-mail: rfriedrich@uke.de

Key Words: Vascular malformation, intraosseous, haemangioma, orbit, cone beam computed tomography, 3D reconstruction, bone mineral density, immunohistochemistry, differential diagnosis. variable. The symptoms of the patient presented herein show that growth phases of a vascular orbital malformation can occur in later stages of life and are initially indistinguishable from a neoplasm. In individual cases, patient care necessitates advanced diagnostic measures to establish the diagnosis and determine surgical therapy.

Hemangiomas and vascular malformations (VM) are common findings in humans. Vascular anomalies may cause significant aesthetic and functional problems (1). In particular, the periorbital and orbital soft tissues can be the region of very noticeable and difficult to treat forms of vascular anomalies and tumours of vascular origin (2-6). However, hemangioma arising from the osseous boundaries of orbital content are usually not considered in analyses of cases, reviews, or textbooks (1, 3-5, 710). Vascular lesions with a locus in the orbital bones are rare (11-17). Reports on this manifestation are individual cases, small case series, and compilations from various collections of case reports $(2,12-33)$. The following report is about an intraosseous lesion of the facial skull, which, due to its unusual localization and presentation in the orbital region, initially directed suspicion to other solid skeletal lesions $(34,35)$. Differential diagnosis has already been facilitated by preoperative imaging. However, the final diagnosis was based on morphological findings.

\section{Case Report}

Clinical findings. A 54-year-old female patient attended the outpatient clinic of the Department of oral and craniomaxillofacial surgery on the initiative of her family doctor, who suspected a solid facial tumor of unknown origin. She had suffered a stroke in the previous year that had healed without residual deficits. This experience had permanently frightened the patient and was, therefore, afraid of further illnesses. On admission, the woman had a symmetrically 
developed, age-appropriate shaped face. The skin's surface was intact and appeared normal according to age. The patient described a painless, slowly increasing mass below the lower edge of the left orbit. No tumor was visible at this point. A firm tumor was palpable on the facial skull bone, adhering to the inferior orbital rim. The firm mass' surface appeared to be round. The skin was easily moved over the bony mass. The patient responded to slight pressure at this point with a moderate sensation of pain. The sensitivity test of the facial skin showed normal innervation of both cheeks and also of the upper teeth. The patient had no history of facial trauma.

Radiographic findings. A radiopaque mass of the left infraorbital rim was visible on cone beam computed tomograms of the midfacial region (Figure 1). The radiopaque mass was fixed with a broad base on the facial skeleton, lateral to the infraorbital foramen. The edges of the lesion were sharply defined. The outer boundary of the lesion showed contrast formation like cortical bone guiding preliminary diagnosis to peripheral osteoma. Nevertheless, this cortex-like aspect was restricted to tumor parts close to the rim. The main part of the lesion was a balloon-like tumor isointense to cancellous bone. However, the whole lesion was heterogeneous, showing small regions isointense to soft tissue. Focal bar-like areas inside the lesion appeared like residual cortical bone. The sectional images suggested an osseous lesion with fluid-filled cavities, so that suspicion of the so-called intraosseous hemangioma was obvious. The patient was recommended to remove the lesion but initially opted for a wait-and-see policy. However, the patient came back to the outpatient clinic 6 weeks later because she had noticed local growth of the lesion and the conspicuous tumor made her feel insecure about the characteristics of the lesion.

Surgery. The patient was treated surgically under general anesthesia. After an infraorbital incision through the lower eyelid, the intact periosteum covering the lesion was cut and pushed aside so that the surface of the lesion was visible (Figure 2). The infraorbital nerve was shown medially to the lesion and protected. The origin of the lesion was the transition area from zygoma to maxilla at the infraorbital margin. The tumor was of a bony consistency, but showed a very thin, lively translucent and focal porous surface. The tumor reached the edge of the orbit and had grown in continuity into the orbital floor. The tumor was cut off with a drill and chisel. The bleeding from the bone wound was minor and quickly treated, then the wound was closed in stages. The wound healing process was uncomplicated; the sensitivity disorder of the infraorbital nerve was slight and decreased within 4 weeks.

Histology. Microscopic examination revealed a benign vascular lesion surrounded by fibrous connective tissue without any cytological atypia. The dilated and ectatic vessels were lined by endothelium and paucicellular smooth muscle stroma of variable thickness. Focal thromboses were present. Immunohistochemistry revealed positivity for endothelial marker CD31 and nuclear positivity for ETS family transcription factor ERG. Staining results were negative for podoplanin (D2-40), glucose transporter protein 1 (GLUT-1), Wilms tumor protein (WT-1) and AA-Mast cell tryptase. The proliferation marker Ki67 did not stain endothelial cells, but inflammatory cells as an internal positive control. In summary, the histological findings were consistent with a cavernous venous malformation, previously termed as orbital cavernous hemangioma (Figure 3).

Micro-computed tomography. The cavernous venous malformation was further examined using a Skyscan $\mu \mathrm{CT}$ 1272 (Bruker, Kontich, Belgium) operated with a spatial resolution of $7.5 \mu \mathrm{m}$ (Figure 4). On microstructural level, the malformation showed a spongy structure composed of rods and plates [Structure model index $(\mathrm{SMI})=1.1938$ ] that resembles cancellous, trabecular bone. Compared to cancellous bone of other regions, e.g. iliac crest or long bones (36), the structure had a bone volume/tissue volume (BV/TV) ratio within the upper range and a slightly higher number of trabeculae, which are less separated and of similar thickness. Mineral density parameters (Tissue mineral density (TMD) and bone mineral density (BMD)), determined after pre-calibration with hydroxyapatite phantoms, were in range of cancellous and cortical bone within other skeletal regions (37). Furthermore, the bone matrix at the trabecular surface was less mineralized than at its center suggesting ongoing mineralization. The fenestrated surface of the expanding bone is visible in detail in the scanning electron microscopic images (Figure 5).

\section{Discussion}

This examination shows that an intraosseous tumor of the periorbital region with tactile findings of a bone tumor and imaging findings of a vascularized osseous lesion can only be definitely classified by morphological analysis. The expression profile of individual antigens in the endothelium is crucial in the differential diagnosis of vascular lesions.

Intraosseous VM and hemangiomas of the orbit and periorbital region are rare findings and, therefore, initially not the first differential diagnosis based on frequency of osseous lesions $(38,39)$. Radiographic differential diagnosis of calvarial lesions of vascular origin includes epidermoid cyst and Langerhans' cell histiocytosis (40). Exophytically growing tumors with a palpable bone-dense surface suggest exostosis or osteoma $(41,42)$, fibrous dysplasia (38), or other even more rare lesions of osseous origin $(38,43)$. Indeed, the paranasal cavities are predilection sites giving rise to osteoma, and these masses of the ethmoid or maxilla 

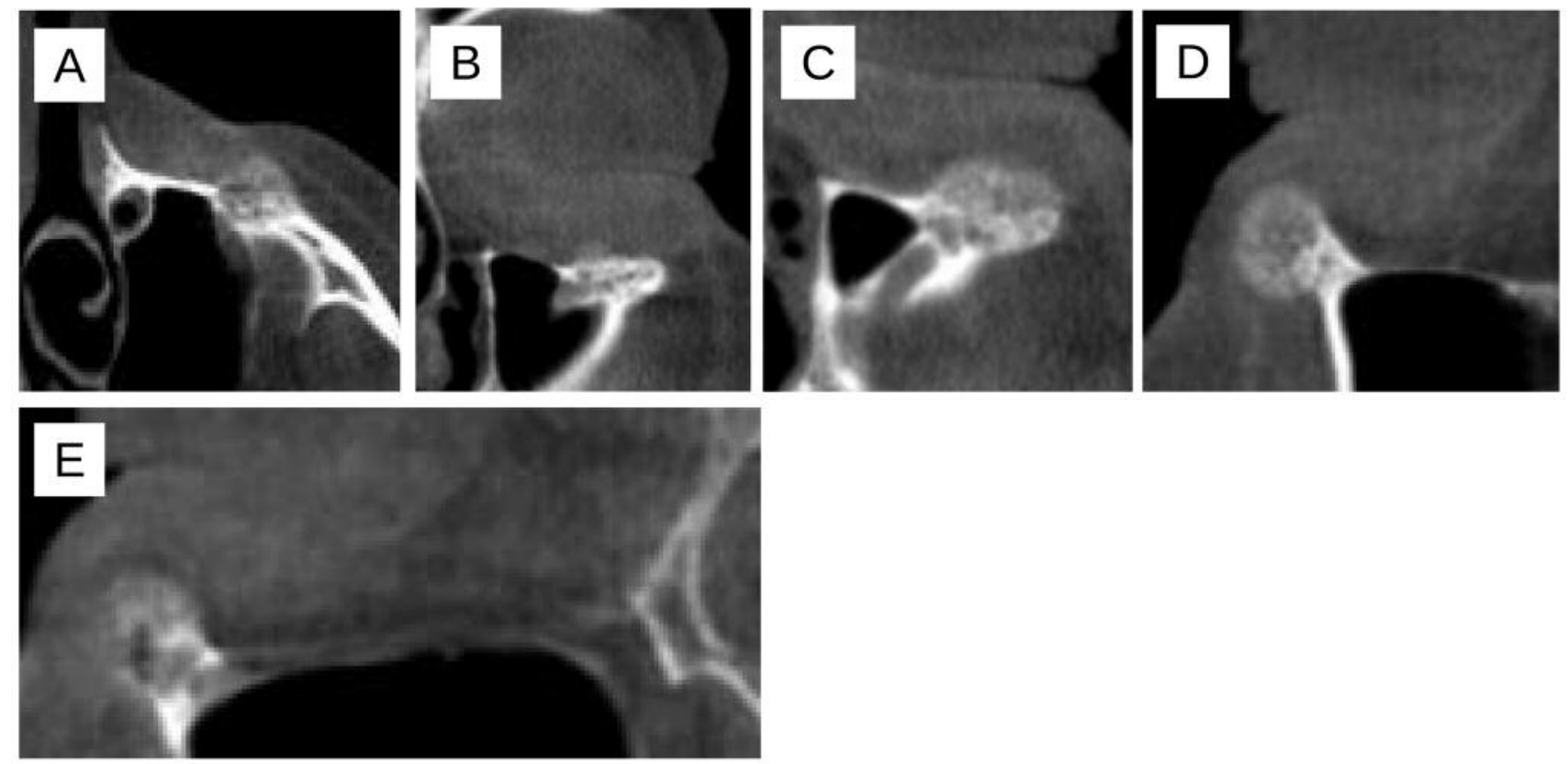

Figure 1. Cone beam computed tomograms of the osseous lesion arising from the left inferior orbital rim. (A) The axial view shows a roundish, inhomogeneous radiopaque lesion infiltrating the orbital rim. (B) The coronal view shows a cortex-like limitation predominantly at the base of the lesion at the rim that in $(C)$ gets lost in the central part of a balloon-like tumor with a sunburst-like internal structure. (D) Sagittal view of orbital rim shows rather radiopaque pedunculated basal tumor part and protruding, less radiopaque, well-defined tumor. While the lesion in (D) merges into the normal orbital rim, portions of the lesion in $(E)$ extend into the infraorbital canal.

can expand into the orbit and periorbital soft tissues (44) Furthermore, VM and hemangioma of the calvaria can grow into the orbit and become symptomatic (45), so infiltration of the orbit can be secondary to a more distant vascular lesion arising at different sites of the skull (18). This report supplements the limited information on the manifestation of orbital intraosseous vascular lesions.

Information on intraosseous vascular lesions often describes findings on frequency, topography, preferred age of manifestation, and gender distribution under the term "hemangioma". The distinction between hemangioma and VM for intraosseous lesions was requested early by some authors (46), but up to now is not generally taken into account (16, $26,47)$. Therefore, up to now, literature references to intraosseous vascular lesions of orbit often relate to hemangioma in general without considering malformations of vascular origin at this site (38).

Frequency of intraosseous hemangioma. The intraosseous development of vascular lesions in the whole skeleton is a frequent finding $(38,48)$. The most common locations of intraosseous hemangiomas are the spine and skull $(40,49)$, followed by other bones $(38,50,51)$. However, the data on prevalence vary greatly from author to author, presumably because the reference relates to very different populations and investigation techniques $(40,52)$. The prevalence of intraosseous hemangioma confined to the vertebral column ranges between $10-27 \%$ in adults (53) or even $37 \%$ (54), depending on the mode of investigation (necropsy, plain radiography, CT, MRI) $(53,54)$. The ethnic background of the study population very likely has an impact on the results (53). Still, many intraosseous hemangiomas remain asymptomatic and are random findings when examining the skeleton (40). In the area of the jaws, the mandible is affected more frequently than the maxilla $(41,55)$. However, manifestations of the jaws are significantly less common than findings on the calvaria (40).

It has been suggested the majority of intraosseous hemangiomas of the facial skull are, in fact, VMs (46). There are no epidemiological data on the distribution of intraosseous VM of the orbit and adjacent bone regions using current morphological criteria. Only a few recently published papers analyze osseous vascular lesions as VM arising in the facial skeleton (56). Most reports or series are based on case reports or a small number of cases (57-60). Indeed, the vast majority of orbital lesions are arising in soft tissues (5).

Localization of intraosseous orbital hemangioma. Henderson (2) has summarized earlier reviews of intraosseous orbital hemangiomas $(20,61)$. Published data show that all bones of the orbital walls may be a locus for a hemangioma $(2,62)$. Intraosseous hemangiomas of the orbit arise in the majority of 

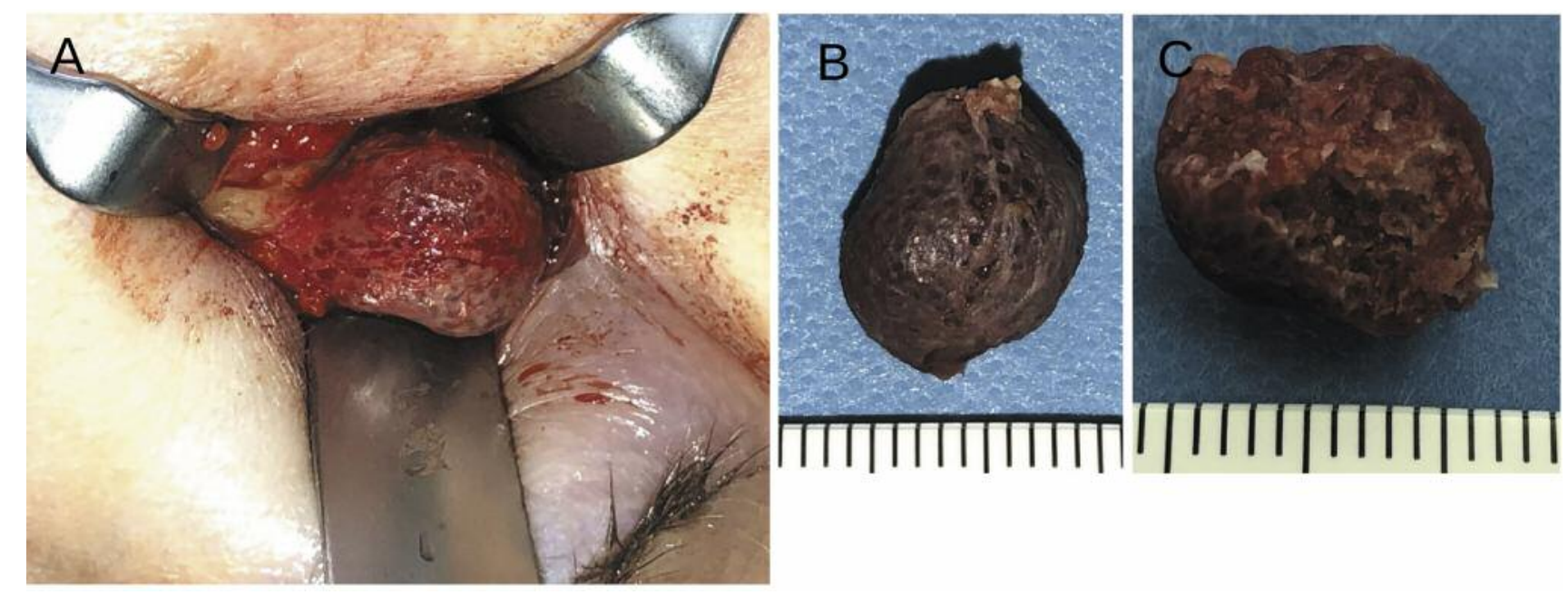

Figure 2. Exposed left infraorbital rim. (A) Incised periosteum covering an osseous lesion with a parchment-thin, porous surface that makes the blood-filled cavities visible. (B and C) Excised specimen with (B) surface and $(C)$ bottom. Large cavities are cut at the base of the lesion.
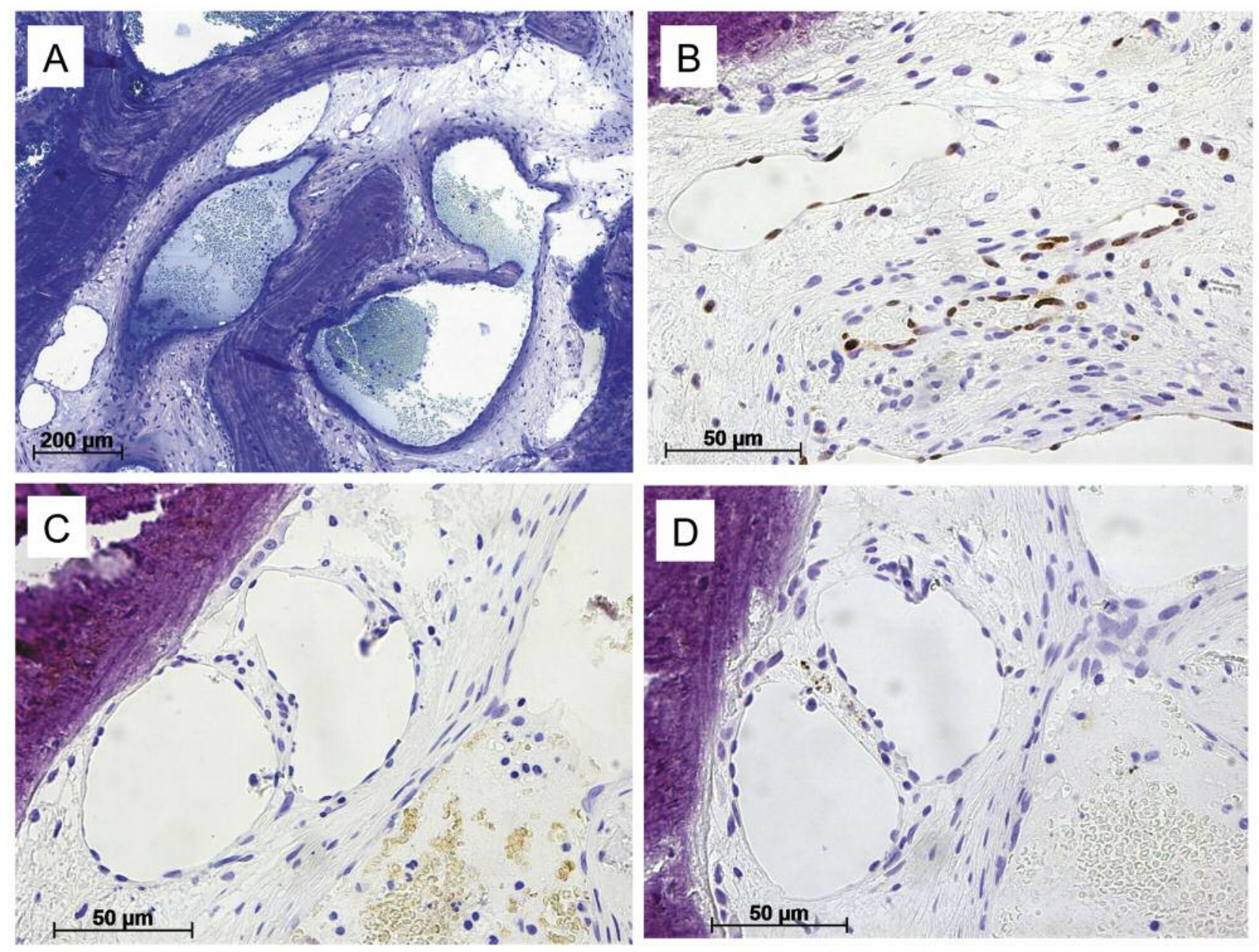

Figure 3. (A) Methyl methacrylate embedded and Toluidin blue stained specimen: Bone with multiple ectatic and blood-filled spaces, lined by endothelium. (B) Immunohistochemistry for ERG stains endothelial lining cells. (C) Endothelium shows negative staining for GLUT-1. (D) Loss of WT-1 expression in endothelium. 

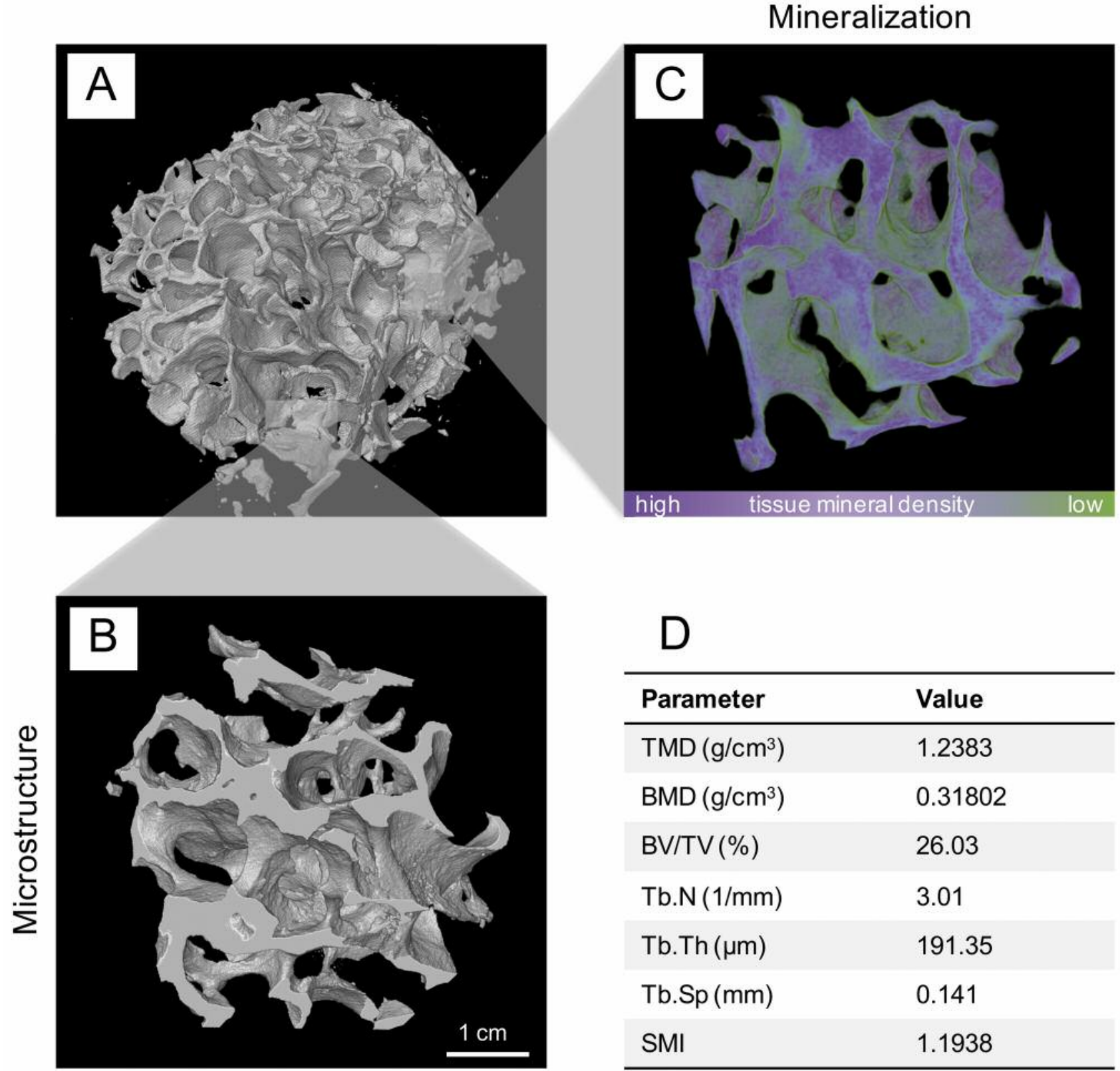

\begin{tabular}{ll}
\multicolumn{1}{c}{$\mathrm{D}$} \\
\hline Parameter & Value \\
\hline $\operatorname{TMD}\left(\mathrm{g} / \mathrm{cm}^{3}\right)$ & 1.2383 \\
$\operatorname{BMD}\left(\mathrm{g} / \mathrm{cm}^{3}\right)$ & 0.31802 \\
$\operatorname{BV} / \mathrm{TV}(\%)$ & 26.03 \\
$\operatorname{Tb} . \mathrm{N}(1 / \mathrm{mm})$ & 3.01 \\
$\operatorname{Tb} . \operatorname{Th}(\mu \mathrm{m})$ & 191.35 \\
$\operatorname{Tb} . S p(\mathrm{~mm})$ & 0.141 \\
$\operatorname{SMl}$ & 1.1938 \\
\hline
\end{tabular}

Figure 4. Micro-computed tomography of the infraorbital osseous lesion. (A, B) The very compact bone normally reinforced at the infraorbital rim is inflated by the soft tissue lesion to a sponge-like structure resembling cancellous bone predominantly composed of plates (SMI). (C) Mineralization of bone matrix is lower at its surface indicating an ongoing formation. (D) Bone mineral density is in the range of normal values, taking reference to values derived from other skeletal regions of healthy individuals as normal standard [tissue mineral density (TMD) range of normal values=1.15-1.24 g/cm3 (37); BV/TV: Bone volumeltissue volume; Tb.N: trabecular number; Tb.Th: trabecular thickness; Tb.Sp: trabecular separation; SMI: structure model index].

cases from the orbital roof (63). The frontal bone is affected in about $50 \%$ of all intraosseous orbital hemangiomas (2). Recent reviews confirm that intraosseous hemangiomas of the orbit preferentially arise from the upper half of the cone (29). The tumors (or potentially VM) arise more frequently in the front sections of the orbit, often the orbital rim (29) than in deep sections of the cone (11), for unknown reasons. In rare cases, bony bulges caused by intraosseous hemangioma are palpable (63).

Age and gender of intraosseous orbital hemangioma. Basically, an intraosseous hemangioma of the orbit can affect any age. The average age group is individuals in the fourth to fifth decade of life (2). Females are affected a little more 
frequently than males (2). Assuming that the majority of intraosseous vascular lesions previously classified as hemangioma are to be reclassified as VM, the patient meets the frequency expectation for this rare lesion according to age and gender.

\section{Imaging diagnostics of intraosseous hemangioma.} Hemangiomas, in general, can often be reliably estimated by clinical assessment without the need for further imaging (64). This assessment applies to many superficial soft tissue lesions, but has narrow limits for the evaluation of deep lesions and lesions with suspected osseous involvement or those that primarily develop intraosseously $(10,14)$. Computed tomography is the imaging technique of choice to delineate intraosseous hemangioma $(14,23,41,65)$. In individual cases, the use of magnetic resonance tomography may be indicated, for example, to differentiate the hemangiomatous infiltration of organs such as the brain or orbital soft tissues $(11,13,16$, $20,30,66)$. Ultrasound examination or angiography can be indicated for extensive lesions in order to assess the flow characteristics or to perform preoperative embolizations (1, 67). However, the penetration depth into the bones is limited for B-scan ultrasound.

Some authors describe typical radiological characteristics allowing intraosseous hemangioma to be recognized with a high degree of probability both on plain radiographs $(68,69)$ and cross-sectional images (24). Cross-sectional images have significantly improved the demonstration of intraosseous lesions $(15,70)$. On the other hand, other authors consider the advantage of CT or MRI diagnostics in the differential diagnosis of intraosseous hemangiomas of the orbit to be unsuccessful for routine use (2). Radiological diagnostic criteria of hemangioma include honeycomb-like rarefication of trabecular structure. Other hemangiomas of osseous origin show a sunburst-like pattern $(15,20)$ (Figure 1). However, these patterns are not necessarily to be expected in intraosseous hemangiomas of the facial skull $(2,11,31,63)$ and are not specific for vascular lesions of bone (71). Indeed, intraosseous vascular lesions of the jaws show a wide range of radiographic findings (41) that also applies to intraosseous VM of the orbit $(2,31,63)$. Evidence to differentiate between an intraosseous hemangioma or VM from imaging cannot be derived from previous publications. Although, an influence on growth of neighboring tissues and organs in childhood is known for VM but was not recorded in hemangioma (72).

Classification of vascular lesions. A distinction is made between hemangiomas (as true neoplasias) and vascular malformations (non-neoplastic malformations of the vascular system) $(70,73,74)$. Hemangioma is a benign tumor of variable size composed of cells involved in the construction and lining of vessels (6). It is believed that a hemangioma may be existing at birth but is not necessarily recognized at this time (73), with exception of so-called congenital hemangioma (70). Hemangioma becomes conspicuous due to disproportional growth in postnatal life and shows involution in many cases (1). Hemangioma does not necessarily infiltrate surrounding structures but can sometimes be destructive. In these characteristics, hemangioma differs from VM, which is defined as a lesion already present at birth (73) growing in proportion to body development (1). Similar to hemangioma, VM may not be noticeable at birth or early childhood. VM is a slowly growing, infiltrative, and destructive lesion. However, these definitions are not generally recognized for distinguishing hemangioma as neoplasia and VM as differentiation disorder (69). It has repeatedly been pointed out that both terms have been referred to as two exchangeable diagnostics and were erroneously used to address different entities with genuinely vascular components. However, there are different entities that may require different therapy $(41,70,73,75)$. However, it is sometimes difficult to apply the defining terms for a vascular lesion if a lesion of vascular origin only becomes symptomatic in a previously unremarkable region of the body at a later stage in life. According to literature reviews, intraosseous orbital lesions (usually termed hemangioma) preferentially are first recorded in individuals in their middle age (2). The unavoidable restrictions on the observability of the vascular lesions' development becoming first symptomatic in later phases of life make it understandable that external local factors of growth induction are sought, especially the impact of local trauma on bone regeneration (19). However, no local traumatic events can be proven in the medical history of many reported cases $(2,21,69)$, with few exceptions $(19,26)$. Thus, in individual cases, the disproportionate growth of the lesion remains an important, but ambiguous diagnostic feature in the vascular lesion.

A historical distinction is made between capillary and cavernous intraosseous hemangiomas (3). Cavernous lesions outweigh capillary-type hemangiomas in intraosseous locations of the facial skull (18). The type of growth of the hemangioma does not influence on the size of the mass or the biological tumor behavior in the orbital region $(13,16)$. Some authors suspect intraosseous capillary hemangiomas can transform into cavernous hemangiomas because transitional forms of both types of hemangioma have been detected in individual cases (38). Other authors consider the terms capillary and cavernous hemangioma to be out of date and alternatively call them superficial, deep, and compound haemangioma according to the depth of the lesion (55). However, this classification refers to soft tissue lesions. A subclassification of intraosseous vascular lesions taking into account infiltration depths, is not known and very likely not applicable.

One attempt to standardize the terminology of vascular lesions was the classification of the International Society for 


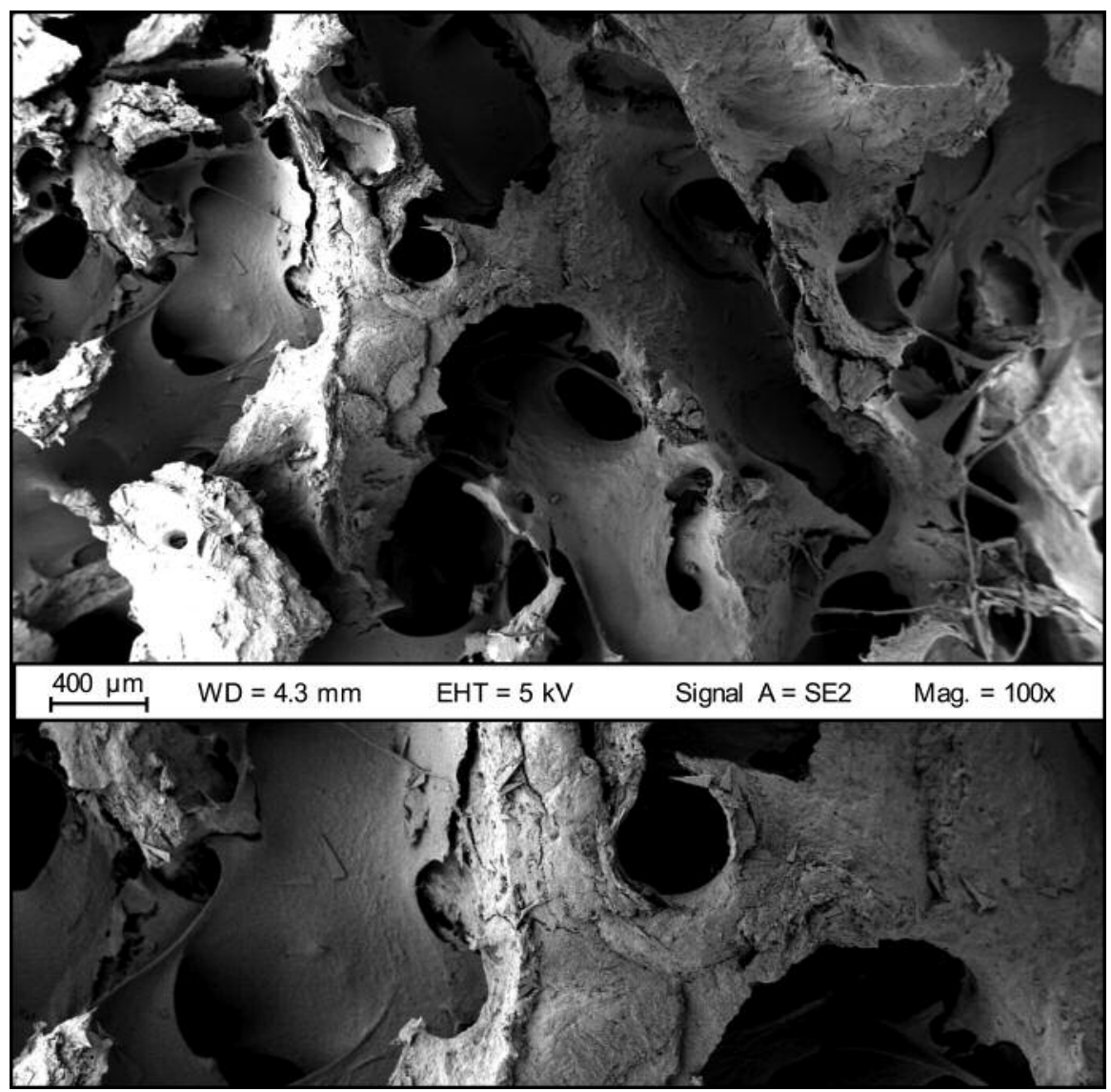

Figure 5. Scanning electron microscopy of the osseous surface. Drying of the infraorbital lesion uncovers the surface of mineralized rods and plates partially coated with soft tissue residues. The lower part of the figure shows a detail of the bone surface at a higher magnification $(W D=$ working distance; $E H T=$ electron high tension).

the Study of Vascular Anomalies (ISSVA) $(70,74)$. In this classification, the undetermined use of the term 'hemangioma' is rejected as misleading. Rather, a distinction should be made between vascular tumors and vascular malformations as individual entities that are classified under the generic term 'vascular anomaly'. Hemangioma is a benign neoplasia of vascular origin to be specified (70). However, the ISSVA classification of vascular anomalies has focused on the definition of soft tissue tumors. Osseous malformations of vascular genesis and vascular bone lesions, in particular, are no subject in the current classification on vascular anomalies (74). Intraosseous hemangiomas can, if at all, be classified under the "others" subgroup $(70,74)$. This may be one reason that the well-established concept of hemangioma is still in use to define intraosseous lesions that show characteristics of a neoplasm (38) and the term has been chosen for the description of the essential finding also in recent reports on this item (13-17, 1926, 29-33). On the other hand, further surveys show that in the periorbital area, VM arising from soft tissue is far more common than those of intraosseous origin (9).
However, there have been individual attempts to apply the classification of vascular lesions, as suggested by ISSVA, to vascular lesions arising in bone (56). Tissue samples from children, adolescents, and young adults $(n=77)$ were examined, because in this age group, the differential diagnosis between malformation and neoplasm is paramount $(1,73)$. Interestingly, there are intraosseous lesions of the calvaria and maxilla analyzed in this study, but no orbital manifestation (56). The authors were able to demonstrate distinguishing features for VM or neoplasm can also be made on lesions of osseous origin. The consequence of re-classified intraosseous lesions was a decrease in the proportion of neoplasms in favor of vascular malformations. Epithelioid hemangioma was the most common entity among confirmed osseous tumors in children and adolescents (56). As a further consequence of their research, the authors conclude that the term 'hemangioma' should only be used if a neoplastic lesion with endothelial proliferation has been diagnosed. The term 'hemangioma' should, if applicable, always be used in conjunction with another qualifying term such as 'infantile', 'spindle cell', or 
'epitheloid' $(56,74)$. Reclassification of orbital cavernous hemangiomas as cavernous venous malformations has also been adopted for soft tissue manifestations of orbital vascular lesions (5). However, this classification has not yet been generally used $(75,76)$. Only in recent analyses, it is pointed out that facial vascular lesions are often entities that should not be classified as hemangioma, but as VM $(52,56-70)$. The radiological criteria of the intraosseous lesions correspond to those that have been used to differentiate hemangiomas (59). Morphological criteria are an essential part of the revised classification to distinguish intraosseous VM $(60,77)$.

Morphological differential diagnosis of hemangioma versus malformation. Morphological assessment plays an essential role in the differential diagnosis of hemangioma vs. vascular malformation (78). Autoradiographic studies have shown that hemangiomateous endothelia, in contrast to malformations, incorporate radioactive thymidine (73). In light microscopy, malformations - in contrast to hemangiomas - lack any mitotic activity (38). Established morphological methods are therefore available to distinguish between the two entities. The mitotic activity can be identified with antibodies directed against cell cycle-associated antigens, for example, molecular immunology borstel 1 (MIB1) antigene. However, contradicting data on mitotic activity of hemangiomas of the orbit as a distinguishing parameter of vascular lesion diagnosis have been published (15). Glucose transporter protein 1 (Glut1) and Wilms tumor protein 1 (WT1) are expressed in vascular cells of haemangiomas and are missing in VM $(38,56)$. The results of a current study suggest that intraosseous vascular lesions of the facial skeleton are predominantly venous malformations. The reclassification is primarily based on Glut1 expression pattern of the lesion's vessels (52). However, the specificity of Glut1 expression as an indicator of hemangioma only seems to apply to manifestations outside the central nervous system. Glut1 has been detected in intracerebral VM (79). For the diagnosis of cutaneous vascular lesions, the detection of Glut1 is an important finding to rule out VM (80). This diagnostic tool was also used to differentiate intraosseous vascular lesions (56). However, the diagnosis of a vascular lesion should not be made dependent on Glut1 expression pattern alone (80).

Therapy of intraosseous vascular lesions. If the entire skeleton is considered, most intraosseous lesions are not treated because they remain asymptomatic, and there is no targeted diagnosis in this area $(38,40)$. The term intraosseous hemangioma is generally used for lesion arising in the entire skeleton $(38,40)$. In the skull area, intraosseous hemangiomas are more likely to develop symptoms, be it due to local sensitivity disorders $(26,29)$, asymmetry of the affected skull area $(21,81)$, bone destruction (39) or functional restrictions, especially in the orbital area $(16,17,29)$. However, complaints are rarely reported in the case of intraosseous orbital hemangioma (55) and are mostly vague pain symptoms (38). Facial contour deformity due to a vascular lesion is not a sufficient reason for surgical treatment for some authors (26).

Treatment consists of surgical removal of the lesion $(22,25$, 81-84) supported by angiological techniques. Bluish discoloration of the exposed osseous lesion (Figure 2) would suggest a vascular lesion (81). For more substantial defects, skeletal reconstructions are necessary $(21,69,81-84)$. Relapses of the lesions are rare (2). Although resection in toto is preferred, good esthetic results are achieved in individual cases even after partial resection without local recurrence $(15,39)$. Adjuvant radiation therapy of hemangioma is not recommended $(14,56)$ because the malignant degeneration of tissues in the radiation field is one of the known late consequences of this therapy of a benign neoplasm (33). However, some authors refer to the radiotherapy option in individual cases (20), predominantly for lesions outside the orbital regions and without the option of surgical therapy $(9,85)$.

\section{Conclusion}

Intraosseous VM of the orbit is a rare finding and, if the course is symptomatic, may require surgical therapy. Crosssectional imaging facilitates the preoperative assessment of the lesion. The extent of the reconstructive measures depends on the size and localization of the osseous lesion. Histological examination of the specimen is mandatory, whereby the histogenetic assignment of the intraosseous lesions arising in this region remains the subject of current research.

\section{Conflicts of Interest}

The Authors have no conflicts of interest with regard to the work presented.

\section{Authors' Contributions}

REF treated the patient and drafted the manuscript. REF and FKK researched the literature relevant to the topic. REF, UG, FKK, SvK and TV performed and analyzed radiographs of patient and tissue sample. AML investigated tissue samples. All Authors contributed to the manuscript and gave final approval for publication.

\section{Acknowledgements}

The patient has given permission for images and details to be published.

\section{References}

1 Van Aalst JA, Bhuller A and Sadove AM: Pediatric vascular lesions. J Craniofac Surg 14: 566-583, 2003. PMID: 12867875. DOI: $10.1097 / 00001665-200307000-00032$

2 Henderson JW: Orbital Tumors. $3^{\text {rd }}$ edition, Raven Press, New York, pp. 175-178, 1994. 
3 Gündüz K and Karcioglu ZA: Vascular Tumors. In: "Orbital Tumors", edited by Z.A. Karcioglu, Springer, New York, pp. 141-162, 2009.

4 De Potter P: Imaging in Orbital Differential Diagnosis. In: "Orbital Tumors", edited by Z.A. Karcioglu, Springer, New York, pp. 94-103, 2009.

5 Rootman DB, Heran MK, Rootman J, White VA, Luemsamran P and Yucel YH: Cavernous venous malformations of the orbit (so-called cavernous haemangioma): A comprehensive evaluation of their clinical, imaging and histologic nature. Br J Ophthalmol 98: 880-888 2014. PMID: 24627253. DOI: 10.1136/bjophthalmol-2013-304460

6 North PE: Classification and pathology of congenital and perinatal vascular anomalies of the head and neck. Otolaryngol Clin North Am 51: 1-39, 2018. PMID: 29217054. DOI: 10.1016/j.otc. 2017.09 .020

7 Richter GT and Friedman AB: Hemangiomas and vascular malformations: current theory and management. Int J Pediatr 2012: 645678, 2012. PMID: 22611412. DOI: 10.1155/2012/645678

8 McNab AA, Selva D, Hardy T and, O'Donnell B: The anatomical location and laterality of orbital cavernous haemangiomas. Orbit 33: 359-362, 2014. PMID: 24831510. DOI: $10.3109 / 01676830.2014 .915329$

9 Sullivan TJ: Vascular anomalies of the orbit-a reappraisal. Asia Pac J Ophthalmol (Phila) 7: 356-363, 2018. PMID: 29633786. DOI: 10.22608/APO.2017151

10 Sadick M, Müller-Wille R, Wildgruber M and Wohlgemuth WA: Vascular anomalies (Part I): Classification and diagnostics of vascular anomalies. Rofo (Fortschr Röntgenstr) 190: 825-835, 2018. PMID: 29874693. DOI: 10.1055/a-0620-8925

11 Sweet C, Silbergleit R and Mehta B: Primary intraosseous hemangioma of the orbit: CT and MR appearance. AJNR Am J Neuroradiol 18: 379-381, 1997. PMID: 9111679.

12 Marx R and Stern D: Oral and Maxillofacial Pathology. Quintessence Publishing, Chicago, pp. 452-453, 2003.

13 Shah NB, White VA, Heran M, Haw C and Rootman J: Simultaneous intraosseous and intradural capillary haemangioma of orbit. $\mathrm{Br} \mathrm{J}$ Ophthalmol 89: 1534-1535, 2005. PMID: 16234472. DOI: $10.1136 /$ bjo.2005.074427

14 Valentini V, Nicolai G, Lorè B and Aboh IV: Intraosseous hemangiomas. J Craniofac Surg 19: 1459-1464, 2008. PMID: 19098533. DOI: 10.1097/SCS.0b013e318188a030

15 Gupta A, Prabhakaran VC, Dodd T, Davis G and Selva D: Orbital cavernous haemangiomas: immunohistochemical study of proliferative capacity, vascular differentiation and hormonal receptor status. Orbit 31: 386-389, 2012. PMID:23088382. DOI: 10.3109/01676830.2012.711887

16 Wu CY, Huang HM, Chen DC, Cho DY and Wei ST: Primary intraosseous hemangioma of the orbital roof: A pitfall of surgery. J Craniofac Surg 27: e580-e581, 2016. PMID: 27428912. DOI: 10.1097/SCS.0000000000002883

17 Choi JS, Bae YC, Kang GB and Choi KU: Intraosseous hemangioma of the orbit. Arch Craniofac Surg 19: 68-71, 2018. PMID: 29609437. DOI: 10.7181/acfs.2018.19.1.68

18 Hook SR, Font RL, McCrary JA and Harper RL: Intraosseous capillary hemangioma of the frontal bone. Am J Ophthalmol 103: 824-827, 1987. PMID: 3591881. DOI: 10.1016/s00029394(14)74401-0

19 Har-El G, Hadar T, Zirkin H and Sidi J: Hemangioma of the zygoma. Ann Plast Surg 18: 533-540, 1987. PMID: 3605990. DOI: $10.1097 / 00000637-198706000-00013$
20 Zucker JJ, Levine MR and Chu A: Primary intraosseous hemangioma of the orbit. Report of a case and review of literature. Ophthalmic Plast Reconstr Surg 5: 247-255, 1989. PMID: 2487230. DOI: 10.1097/00002341-198912000-00004

21 Hirano S, Shoji K, Kojima H, and Omori K: Use of hydroxyapatite for reconstruction after surgical removal of intraosseous hemangioma in the zygomatic bone. Plast Reconstr Surg 100: 86-90, 1997. PMID: 9207663. DOI: 10.1097/00006534199707000-00015

22 Pinna V, Clauser L, Marchi M and Castellan L: Haemangioma of the zygoma: Case report. Neuroradiology 39: 216-218, 1997. PMID: 9106298. DOI: 10.1007/s002340050397

23 Colombo F, Cursiefen C, Hofmann-Rummelt C and Holbach LM: Primary intraosseous cavernous hemangioma of the orbit. Am J Ophthalmol 131: 151-152, 2001. PMID: 11163002. DOI: 10.1016/s0002-9394(00)00649-8

24 Moore SL, Chun JK, Mitre SA and Som PM: Intraosseous hemangioma of the zygoma: CT and MR findings. AJNR Am J Neuroradiol 22: 1383-1385, 2001. PMID: 11498432.

25 Taylan G, Yildirim S, Gideroğlu K and Aköz T: Conservative approach in a rare case of intrazygomatic hemangioma. Plast Reconstr Surg 112: 1490-1492, 2003. PMID: 14504546. DOI: 10.1097/01.PRS.0000080511.23265.24

26 Cheng NC, Lai DM, Hsie MH, Liao SL and Chen YB: Intraosseous hemangiomas of the facial bone. Plast Reconstr Surg 117: 2366-2372, 2006. PMID: 16772943. DOI: 10.1097/01.prs.0000218818.16811.9b

27 Goisis M, Biglioli F, Guareschi M, Autelitano L and Brusati R: Primary intraosseous hemangiomas of the orbit. Orbit 25: 137-139, 2006. PMID: 16754225 . DOI: $10.1080 / 01676830600669247$

28 Torres-Carranza E, García-Perla A, Infante-Cossío P, AcostaFeria M, Belmonte-Caro R and Gutiérrez-Pérez JL: [Primary intraosseous hemangioma of the orbit: report of two cases]. Neurocirugia (Astur) 18:320-325, 2007. PMID: 17882339. DOI: 10.4321/s1130-14732007000400005

29 Madge SN, Simon S, Abidin Z, Ghabrial R, Davis G, McNab A and Selva D: Primary orbital intraosseous hemangioma. Ophthalmic Plast Reconstr Surg 25: 37-41, 2009. PMID: 19273921. DOI: 10.1097/IOP.0b013e318192a27e

$30 \mathrm{Xu} \mathrm{P}$, Lan S, Liang Y and Xiao Q: Multiple cavernous hemangiomas of the skull with dural tail sign: a case report and literature review. BMC Neurol 13: 155, 2013. PMID: 24161077. DOI: $10.1186 / 1471-2377-13-155$

31 Hwang K: Intraosseous hemangioma of the orbit. J Craniofac Surg 11: 386-387, 2000. PMID: 11314388. DOI: 10.1097/00001665200011040-00020

32 Marcinow AM, Provenzano MJ, Gurgel RK and Chang KE: Primary intraosseous cavernous hemangioma of the zygoma: a case report and literature review. Ear Nose Throat J 91: 210, 212, 214215, 2012. PMID: 22614558. DOI: 10.1177/014556131209100512

33 Cassoni A, Terenzi V, Battisti A, Della Monaca M and Oriana RZ: Progressive swelling of the maxilla arising in the radiation site of a congenital hemangioma in a 63-year-old woman. J Craniofac Surg 26: 952-953, 2015. PMID: 25850869. DOI: 10.1097/SCS.0000000000001423.

34 Friedrich RE: Long-term follow-up control of pedunculated orbital floor osteoma becoming symptomatic by atypical facial pain. In Vivo 23: 117-121, 2009. PMID: 19368135.

35 Matthies L, Rolvien T, Pakusa TJ, Knipfer C, Gosau M, Amling $\mathrm{M}$, Friedrich RE and Zustin J: Osteoid osteoma of the mandible 
- clinical and histological findings. Anticancer Res 39: 291-296, 2019. PMID: 30591471. DOI: 10.21873/anticanres.13110

36 Cohen A, Dempster DW, Müller R, Guo XE, Nickolas TL, Liu XS, Zhang XH, Wirth AJ, van Lenthe GH, Kohler T, McMahon DJ, Zhou H, Rubin MR, Bilezikian JP, Lappe JM, Recker RR and Shane E: Assessment of trabecular and cortical architecture and mechanical competence of bone by high-resolution peripheral computed tomography: comparison with transiliac bone biopsy. Osteoporos Int 21: 263-273, 2010. PMID: 19455271. DOI: 10.1007/s00198-009-0945-7

37 Molino G, Dalpozzi A, Ciapetti G, Lorusso M, Novara C, Cavallo M, Baldini N, Giorgis F, Fiorilli S and Vitale-Brovarone $\mathrm{C}$ : Osteoporosis-related variations of trabecular bone properties of proximal human humeral heads at different scale lengths. J Mech Behav Biomed Mater 100: 103373, 2019. PMID: 31369957. DOI: $10.1016 /$ j.jmbbm.2019.103373

38 Freyschmidt J, Ostertag H and Jundt G: Knochentumoren mit Kiefertumoren. Springer, Heidelberg, pp. 606-649, 2010.

39 Yan J, Zhou S and Li Y: Benign orbital tumors with bone destruction in children. PLoS One 7: e32111, 2012. PMID: 22384155. DOI: $10.1371 /$ journal.pone.0032111

40 Wenger DE and Wold LE: Benign vascular lesions of bone: Radiologic and pathologic features. Skeletal Radiol 29: 63-74, 2000. PMID: 10741493. DOI: 10.1007/s002560050012

41 Chandra SR, Chen E, Cousin T and Oda D: A case series of intraosseous hemangioma of the jaws: Various presentations of a rare entity. J Clin Exp Dent 9: e1366-e1370, 2017. PMID: 29302291. DOI: $10.4317 /$ jced.54285

42 Bagheri A, Feizi M and Rezai Kanavi M: Superficial orbital rim osteoma. J Craniofac Surg 30: 2542-2543, 2019. PMID: 31232994. DOI: $10.1097 /$ SCS.0000000000005686

43 Wen Y and Yan J: Primary Tumors of the Orbital Bone. J Craniofac Surg 27: e344-e348, 2016. PMID: 27152568. DOI: 10.1097/SCS.0000000000002510

44 Samil KS, Yasar C, Ercan A, Hanifi B and Hilal K: Nasal cavity and paranasal sinus diseases affecting orbit. J Craniofac Surg 26: e348-e351, 2015. PMID: 26080260. DOI: 10.1097/SCS.00000 00000001827

45 Pastore FS, De Caro GM, Faiola A, Mauriello A and Giuffrè R: Cavernous hemangioma of the parietal bone. Case report and review of the literature. Neurochirurgie 45: 312-315, 1999. PMID: 10599060.

46 Kaban LB and Mulliken JB: Vascular anomalies of the maxillofacial region. J Oral Maxillofac Surg 44: 203-213, 1986. PMID: 3456442. DOI: 10.1016/0278-2391(86)90109-6

47 Gupta T, Rose GE, Manisali M, Minhas P, Uddin JM and Verity DH: Cranio-orbital primary intraosseous haemangioma. Eye (Lond) 27: 1320-1323, 2013. PMID: 23989119. DOI: 10.1038 /eye 2013.162

48 Schmorl G and Junghanns H: The Human Spine in Health and Disease. $2^{\text {nd }}$ Edition, Grune and Stratton, New York, pp. 268296, 1971.

49 Gaudino S, Martucci M, Colantonio R, Lozupone E, Visconti E, Leone A and Colosimo C: A systematic approach to vertebral hemangioma. Skeletal Radiol 44: 25-36, 2015. PMID: 25348558. DOI: 10.1007/s00256-014-2035-y

50 Ogose A, Hotta T, Morita T, Takizawa T, Ohsawa H and Hirata Y: Solitary osseous hemangioma outside the spinal and craniofacial bones. Arch Orthop Trauma Surg 120: 262-266, 2000. PMID: 10853892. DOI: 10.1007/s004020050461
51 Kaleem Z, Kyriakos M and Totty WG: Solitary skeletal hemangioma of the extremities. Skeletal Radiol 29: 502-513, 2000. PMID: 11000295. DOI: 10.1007/s002560000251

52 Srinivasan B, Chan E, Mellor T, Ramchandani $\mathrm{P}$ and Ethunandan M: Intraosseous venous malformation of the craniofacial region: diagnosis and management. Br J Oral Maxillofac Surg 57: 1143-1147, 2019. PMID: 31733879. DOI: 10.1016/j.bjoms.2019.10.308

53 Barzin M and Maleki I: Incidence of vertebral hemangioma on spinal magnetic resonance imaging in Northern Iran. Pak J Biol Sci 12: 542-544, 2009. PMID: 19580008. DOI: 10.3923/pjbs.2009.542.544

54 Webb JR and Beall LE: Incidence of vertebral hemangiomas at magnetic resonance imaging. Skeletal Radiol 34: 592, 2005. PMID: 16132977. DOI: 10.1007/s00256-005-0959-y

55 Ethunandan $M$ and Mellor TK: Haemangiomas and vascular malformations of the maxillofacial region - a review. Br J Oral Maxillofac Surg 44: 263-272, 2006. PMID: 16107299. DOI: 10.1016/j.bjoms.2005.06.032

56 Bruder E, Perez-Atayde AR, Jundt G, Alomari AI, Rischewski J, Fishman SJ, Mulliken JB and Kozakewich HP: Vascular lesions of bone in children, adolescents, and young adults. A clinicopathologic reappraisal and application of the ISSVA classification. Virchows Arch 454: 161-179, 2009. PMID: 19107514. DOI: 10.1007/s00428-008-0709-3

57 Srinivasan B, Ethunandan M, Van der Horst C and Markus AF: Intraosseous 'haemangioma' of the zygoma: more appropriately termed a venous malformation. Int J Oral Maxillofac Surg 38: 1066-1070, 2009. PMID: 19574025. DOI: 10.1016/j.jom. 2009.05.010

58 Kadlub N, Dainese L, Coulomb-L'Hermine A, Galmiche L, Soupre V, Lepointe HD, Vazquez MP and Picard A: Intraosseous haemangioma: semantic and medical confusion. Int $\mathrm{J}$ Oral Maxillofac Surg 44: 718-724, 2015. PMID: 25703595. DOI: 10.1016/j.ijom.2015.01.025

59 Werdich XQ, Jakobiec FA, Curtin HD and Fay A: A clinical, radiologic, and immunopathologic study of five periorbital intraosseous cavernous vascular malformations. Am J Ophthalmol 158: 816-826.e1. PMID: 25034115. DOI: 10.1016/j.ajo.2014.07.004

60 Taleb R, Koutlas IG and Argyris PP: Immunohistochemical and histochemical characterization of intraosseous arteriovenous malformations of the jaws: analysis of 16 cases with emphasis on GLUT-1 immunophenotype. Oral Surg Oral Med Oral Pathol Oral Radiol 124: 165-174, 2017. PMID: 28602263. DOI: 10.1016/j.oooo.2017.04.008

61 Relf SJ, Bartley GB and Unni KK: Primary orbital intraosseous hemangioma. Ophthalmology 98: 541-546, 1991. PMID: 2052311.

62 Jeong WJ and Rhee CS: Primary intraosseous orbital hemangioma of the lacrimal bone. Jpn J Ophthalmol 50: 189190, 2006. PMID: 16604402. DOI: 10.1007/s10384-005-0283-Z

63 Hosten N: Auge und Orbita. Radiologische Differentialdiagnostik. Thieme, Stuttgart, pp. 92, 1995.

64 Werner JA, Eivazi B, Folz BJ and Dünne AA: [State of the art of classification, diagnostics and therapy for cervicofacial hemangiomas and vascular malformations]. Laryngorhinootol 85: 883-891, 2006. PMID: 17171582. DOI: 10.1055/s-2006-944940

65 Young SM, Kim YD, Lee JH and Woo KI: Radiological analysis of orbital cavernous hemangiomas: A review and comparison between computed tomography and magnetic resonance 
imaging. J Craniofac Surg 29: 712-716, 2018. PMID: 29381625. DOI: $10.1097 /$ SCS.0000000000004291

66 Kiratli $\mathrm{H}$ and Orhan M: Multiple orbital intraosseous hemangiomas. Ophthalmic Plast Reconstr Surg 14: 345-348, 1998. PMID: 9783286.

67 Gold L, Nazarian LN, Johar AS and Rao VM: Characterization of maxillofacial soft tissue vascular anomalies by ultrasound and color Doppler imaging: an adjuvant to computed tomography and magnetic resonance imaging. J Oral Maxillofac Surg 61: 1931, 2003. PMID: 12524603. DOI: 10.1053/joms.2003.50003

68 Sherman RS and Wilner D: The roentgen diagnosis of hemangioma of bone. Am J Roentgenol Radium Ther Nucl Med 86: 1146-1159, 1961. PMID: 13911727.

69 Tang Chen YB, Wornom IL $3^{\text {rd }}$ and Whitaker LA: Intraosseous vascular malformations of the orbit. Plast Reconstr Surg 87: 946949, 1991. PMID: 2017505. DOI: 10.1097/00006534-19910500000022

70 Merrow AC, Gupta A, Patel MN and Adams DM: 2014 Revised classification of vascular lesions from the International Society for the Study of Vascular Anomalies: Radiologic-pathologic update. Radiographics 36: 1494-1516, 2016. PMID: 27517361. DOI: $10.1148 / \mathrm{rg} .2016150197$

71 White JA, Ramer N, Wentland TR, Cohen M: The rare radiographic sunburst appearance of odontogenic myxomas: A case report and review of the literature. Head Neck Pathol, 2020. PMID: 31902092. DOI: 10.1007/s12105-019-01122-1

72 Boyd JB, Mulliken JB, Kaban LB, Upton J $3^{\text {rd }}$ and Murray JE: Skeletal changes associated with vascular malformations. Plast Reconstr Surg 74: 789-797, 1984. PMID: 6239297. DOI: 10.1097/00006534-198412000-00010

73 Mulliken JB and Glowacki J: Hemangiomas and vascular malformations in infants and children: a classification based on endothelial characteristics. Plast Reconstr Surg 69: 412-422, 1982. PMID: 7063565. DOI: 10.1097/00006534-19820300000002

74 Dasgupta R and Fishman SJ: ISSVA classification. Semin Pediatr Surg 23: 158-161, 2014. PMID: 25241091. DOI: 10.1053/j.sempedsurg.2014.06.016

75 Hassanein AH, Mulliken JB, Fishman SJ, and Greene AK: Evaluation of terminology for vascular anomalies in current literature. Plast Reconstr Surg 127: 347-351, 2011. PMID: 21200229. DOI: 10.1097/PRS.0b013e3181f95b83

76 McNab AA, Tan JS, Xie J, Selva D, Hardy TG, Starte J and O'Donnell B: The natural history of orbital cavernous hemangiomas. Ophthalmic Plast Reconstr Surg 31: 89-93, 2015. PMID: 24927030. DOI: 10.1097/IOP.0000000000000176
77 North PE, Waner M, Mizeracki A and Mihm MC Jr: GLUT1: A newly discovered immunohistochemical marker for juvenile hemangiomas. Hum Pathol 31: 11-22, 2000. PMID: 10665907. DOI: $10.1016 / \mathrm{s} 0046-8177(00) 80192-6$

78 Glowacki J and Mulliken JB: Mast cells in hemangiomas and vascular malformations. Pediatrics 70: 48-51, 1982. PMID: 7088632.

79 Meijer-Jorna LB, Aronica E, van der Loos CM, Troost D and van der Wal AC: Congenital vascular malformations - cerebral lesions differ from extracranial lesions by their immune expression of the glucose transporter protein GLUT1. Clin Neuropathol 31: 135-141, 2012. PMID: 22551917. DOI: $10.5414 / \mathrm{np} 300446$

80 van Vugt LJ, van der Vleuten CJM, Flucke U and Blokx WAM: The utility of GLUT1 as a diagnostic marker in cutaneous vascular anomalies: A review of literature and recommendations for daily practice. Pathol Res Pract 213: 591-597, 2017. PMID: 28552538. DOI: 10.1016/j.prp.2017.04.023

81 Sary A, Yavuzer R, Latfoğlu O and Celebi MC: Intraosseous zygomatic hemangioma. Ann Plast Surg 46: 659-660, 2001. PMID: 11405376. DOI: 10.1097/00000637-200106000-00023

82 Koybasi S, Saydam L and Kutluay L: Intraosseous hemangioma of the zygoma. Am J Otolaryngol 24: 194-197, 2003. PMID: 12761710. DOI: 10.1016/s0196-0709(02)32429-3

83 Johnson J, Karni R and Ho T: Osteofascial radial forearm free flap reconstruction of midface defect after resection of intraosseous hemangioma. J Craniofac Surg 29: 754-756, 2018. PMID: 29485562. DOI: 10.1097/SCS.0000000000004383

84 Temerek AT, Ali S and Shehab MF: Computer guided resection and reconstruction of intra-osseous zygomatic hemangioma: Case report and systematic review of literature. Int J Surg Case Rep 66: 240256, 2019. PMID: 31874384. DOI: 10.1016/j.jjscr.2019.12.015

85 Alexander J, Meir A, Vrodos $\mathrm{N}$ and Yau YH: Vertebral hemangioma: an important differential in the evaluation of locally aggressive spinal lesions. Spine (Phila Pa 1976) 35: E917-E920, 2010. PMID: 21381257. DOI: 10.1097/brs.0b013e3181ddfb24
Received April 8, 2020

Revised April 17, 2020

Accepted April 29, 2020 